\title{
Progressive ultrastructural changes in the casein matrix during the ripening of inadequately acidified feta cheese
}

\author{
Almut H. Vollmer, ${ }^{1 *}$ Nabil N. Youssef, ${ }^{1}$ James A. Powell, ${ }^{2}$ and Donald J. McMahon ${ }^{1}$ \\ ${ }^{1}$ Department of Nutrition, Dietetics and Food Sciences, Utah State University, Logan 84322 \\ ${ }^{2}$ Department of Mathematics and Statistics, Utah State University, Logan 84322
}

\section{ABSTRACT}

This study investigated the ultrastructural changes underlying the undesired softening of insufficiently acidified feta cheese during cold storage. Experimental feta cheeses with a range of $\mathrm{pH}$ values before brining were manufactured by allowing the cheese blocks to ferment overnight at 3 temperatures $\left(35,20\right.$, and $3^{\circ} \mathrm{C}$ ), which resulted in $\mathrm{pH}$ values of $4.80,4.88$, and 5.17 , respectively. Cheese blocks were stored in $\mathrm{pH}$-adjusted whey brine solutions for up to $120 \mathrm{~d}$, at which point significant decreases in the cheese firmness were confirmed with compression and shear tests. Samples for transmission electron microscopy were taken during the make procedure, after overnight fermentation, and after 7 and $90 \mathrm{~d}$ of cold storage. Increasing the initial $\mathrm{pH}$ from 4.80 to 5.17 resulted in a fundamentally different ultrastructure at d 90, with the protein matrix as the continuous phase having markedly decreased density compared with the typically open porous and discontinuous protein matrix of high density in the low$\mathrm{pH}$ control feta cheese. Ultrastructural changes were progressive, and the first signs were evident after only $20 \mathrm{~h}$ (the overnight fermentation), when fine, proteinaceous material dissociated from the edges of the casein strands into the serum phase. By d 7, the serum phase was completely filled with the loosely aggregated casein closely surrounding the spheroidal fat globules. A further breakdown of the protein matrix was observed after $90 \mathrm{~d}$, with the complete loss of open porous network structure. Image analysis quantitatively confirmed the progressive and significant decrease in density of the protein matrix. In summary, this is the first study to provide a comprehensive and in-depth view of the progressive and most likely irreversible ultrastructural changes that lead to this textural defect.

Key words: transmission electron microscopy, microstructure, ultrastructure, texture

Received January 29, 2019.

Accepted May 10, 2019.

*Corresponding author: almut.vollmer@usu.edu

\section{INTRODUCTION}

Besides appearance and flavor, texture is a key factor in consumer acceptability of foods (Bourne, 2002). Texture plays a critical role in evaluating food quality, and although an abnormal texture does not necessarily signal food spoilage, it is often reason for consumer dislike and rejection. Without textural cues, many foods are also difficult to fully identify (Schiffman, 1977; Schiffman et al., 1978).

Food texture does not refer to a single property of food; rather, it denotes a group of functional attributes ranging from mechanical characteristics (i.e., hardness, cohesiveness) to geometrical (i.e., particle size, shape, and orientation) and other (i.e., moisture and fat content) characteristics in addition to the perception of these as a whole by the consumer. Although there are many different definitions of food texture in the literature reflective of the multitude of parameters affecting it and the specific commodity under investigation, the general consensus is that the textures of foods are derived from their structure (Bourne, 2002) and that understanding the structure is crucial to understanding food behavior (Aguilera, 2005). Most components in food systems, however, are too small to see with the unaided eye, and thus various microscopy techniques have been used to directly visualize the microstructure and ultrastructure in an attempt to establish structurefunction relationships in these food systems (Twyman, 2005). The majority of published studies analyzing the microstructure of dairy systems rely on optical microscopy and scanning electron microscopy, likely due to ease of access and simpler sample preparation, lower cost, and faster turnaround. By contrast, far fewer studies using transmission electron microscopy (TEM), especially at higher magnifications, are seen in the literature (Knoop and Buchheim, 1980). Of those, only some have used image analysis for relative quantitative TEM (Cooke et al., 1995; Paulson et al., 1998; Reis and Malcata, 2011). However, systematic ultrastructural analysis with and without statistical image analysis has the potential to provide unparalleled insights into 
mechanisms of texture development in dairy systems, and therefore its value cannot be overemphasized.

Cheeses exhibit many different textures related to compositional and manufacturing techniques (Fox et al., 2004). However, each type of cheese has its own characteristic texture that the consumer has come to expect. For example, fresh mozzarella cheese is moist and soft, whereas processed mozzarella cheese is firmer and more rubbery with good stretch and melting behavior (Tunick et al., 1993). Young cheddar cheese is springy but gets harder and more brittle with prolonged aging (Pollard et al., 2003). Swiss cheese is soft, smooth, and elastic with characteristic eyes produced by propionic acid fermentation (Froehlich-Wyder and Bachmann, 2004). Cream cheese is also soft but with a spreadable texture (Kalab et al., 1981). Mature surface mold-ripened cheeses, such as Camembert or Brie, have a buttery, smooth, almost runny interior under a white bloomy rind (Spinnler and Gripon, 2004).

Although textural changes during the ripening process are known to occur and are in most cases desirable, deviations from characteristic textures of the final product are much less tolerated. Such deviations, leading to an unacceptably soft, almost mushy texture, have been anecdotally reported from industry and artisan cheese makers of aged feta cheese. Feta cheese is a well-known and popular pickled cheese, the origin of which traces back to ancient Greece (Anifantakis, 1991). It is a rennet-set, brined white cheese without a rind that has low $\mathrm{pH}$ and high salt in moisture. Feta normally has a short, firm, and smooth texture that breaks easily into pieces when compressed. Abd El-Salam and Alichanidis (2004) suggested that insufficient acidity before brining and inadequate salt distribution during brining produces abnormally soft aged feta cheeses. The $\mathrm{pH}$ of cheese is an important process parameter, and changing cheese $\mathrm{pH}$ has been demonstrated to affect texture in several cheese varieties, such as mozzarella cheese (Kindstedt et al., 2001; Sheehan and Guinee, 2004; Cortez et al., 2008), cream cheese (Almena-Aliste and Kindstedt, 2005; Almena-Aliste et al., 2006; Monteiro et al., 2009), and feta cheese (McMahon et al., 2009).

Our goal was to produce 3 feta cheeses with different initial $\mathrm{pH}$ by fermenting the cheese at different temperatures before immersing the cheese in cold brine. The ultrastructure of these cheeses during the manufacture and ripening process was investigated with TEM combined with statistical image analysis methods of the protein matrix with the aim of understanding the structural changes leading to the soft texture. The detailed structural information gained here provides a useful chronological framework for industrial and artisanal cheese makers.

\section{MATERIALS AND METHODS}

\section{Milk Collection and Cheese Manufacture}

Fresh bovine milk obtained from the George B. Caine Dairy Research and Teaching Center (Wellsville, UT) was pasteurized $\left(72^{\circ} \mathrm{C}\right.$ for $\left.15 \mathrm{~s}\right)$ at the Gary Haight Richardson Dairy Products Laboratory at Utah State University (Logan, UT). Feta cheese was made in the same laboratory using $136 \mathrm{~kg}$ of pasteurized whole milk with a protein:fat ratio of 0.72 and $\mathrm{pH}$ of 6.70 . Milk was heated to $35^{\circ} \mathrm{C}$, inoculated with $8 \mathrm{~g}$ of freeze-dried concentrated lactic cultures for direct vat inoculation (Choozit FT 002, Danisco, DuPont, Wilmington, DE) and $1 \mathrm{~g}$ of adjunct Lactobacillus rhamnosus culture (Holdbac LC, Danisco), supplemented with $8 \mathrm{~g}$ of kid lipase (no. 300, Chr. Hansen Inc., Milwaukee, WI), and renneted with $12 \mathrm{~mL}$ of chymosin (57 international milk clotting units/kg of milk, Chy-Max, Chr. Hansen Inc.). The curd was cut after 30 min using wire knives with 16-mm spacing and healed for $15 \mathrm{~min}$ followed by gentle stirring. When curd $\mathrm{pH}$ reached 6.4 , whey was removed to curd level, and curd and remaining whey were transferred to 3 perforated cheese molds where curd was pressed under its own weight and whey was allowed to drain. The molds were turned 4 times at 30 -min intervals followed by overnight storage $(\sim 20 \mathrm{~h})$ of the molds in plastic containers at 35,20 , and $3^{\circ} \mathrm{C}$, respectively, to produce cheeses of different $\mathrm{pH}$ before brining. Curd, cheese, and whey $\mathrm{pH}$ was measured using a glass electrode.

\section{Cheese Brining and Storage}

After overnight fermentation, cheese was removed from the molds and cut into blocks (approximately 10 $\times 8 \times 5 \mathrm{~cm}$ ), and $\mathrm{pH}$ was measured. Brine solutions were prepared by adding $14 \%$ (wt/wt) of $\mathrm{NaCl}$ to whey that had been retained after cheese making and acidified using acetic acid to match cheese $\mathrm{pH}$. Cheese was packed into a container and brine was added to cheese in a 1:2 ratio and then stored at $3^{\circ} \mathrm{C}$.

\section{Cheese Texture Determination}

Cheese hardness after $120 \mathrm{~d}$ of storage was determined with uniaxial force-compression tests and shearing tests. Cheese cubes with an approximate side length of $2 \mathrm{~cm}$ were cut from the center of a cheese block and kept at $4^{\circ} \mathrm{C}$ in a plastic container until all measurements were completed. All tests were performed with a texture analyzer (TMS-Pro, Food Technology Corp., Sterling, VA) fitted with a $50-\mathrm{N}$ load cell. A platen (50 $\mathrm{mm}$ in diameter) was used to compress the cubes at 
$0.5 \mathrm{~mm} / \mathrm{s}$ to $70 \%$ of initial height. Hardness was determined by the maximum force recorded for compressing the sample to $70 \%$ of initial height (Szczesniak, 1963). An $80-\mathrm{mm}$ frame support with a fine wire $(0.3 \mathrm{~mm}$ diameter) was used to completely shear the sample at the same speed. Maximum shear force was identified from the shearing profile as the largest recorded peak.

\section{TEM}

Materials. When not otherwise stated, materials used for sample preparation were obtained from Electron Microscopy Sciences (Hatfield, PA).

Sample Collection. Samples for TEM were taken before cutting, after whey predraw, after block formation, after overnight fermentation, and after 7 and $90 \mathrm{~d}$ of storage in cold brine.

Sample Preparation. Pea-sized samples of milk gel were taken with a spatula and carefully transferred to vials filled with fixative (formaldehyde-glutaraldehyde, $2.5 \%$ each in $0.1 M$ sodium cacodylate buffer, $\mathrm{pH} 7.4$ ). Similarly sized small curd particles were directly placed in fixative, whereas cheese samples were cut from the center of cheese blocks into strips $(3 \times 3 \times 5 \mathrm{~mm})$. All samples were kept overnight in fixative at $4^{\circ} \mathrm{C}$ before further reducing the sample size to approximately $1-\mathrm{mm}^{3}$ cubes with a sharp razor blade. After fixation, samples (10-20 cubes per treatment) were rinsed in 2 changes of cacodylate buffer ( $\mathrm{pH} 7.4$ ), postfixed in $2 \%$ aqueous osmium tetroxide for $1 \mathrm{~h}$ at room temperature, and rinsed twice with Nanopure water. Samples were gradually dehydrated in ethanol-water solutions (10 min each in $50 \%, 70 \%$, twice in $95 \%$, and 4 times in $100 \% \mathrm{EtOH})$ and transitioned into Epon plastic resin with 4 changes of pure acetone (10 min each). Samples were then gradually infiltrated with resin-acetone mixtures (1:1 for $1 \mathrm{~h}$, then $3: 1$ overnight) followed by 3 changes with pure resin $(1 \mathrm{~h}$ on a rotator and $1 \mathrm{~h}$ under vacuum). Six cubes per treatment were randomly selected and individually flat-embedded and polymerized overnight at $65^{\circ} \mathrm{C}$. Polymerized blocks were trimmed and thick sections $(\sim 500 \mathrm{~nm})$ were cut with a glass knife on a Leica EM UC6 ultramicrotome (Leica Microsystems Inc., Buffalo Grove, IL), stained with Toluidine Blue, and analyzed for regions of interest with a light microscope before proceeding to cutting ultrathin sections $(70-100 \mathrm{~nm})$ with a diamond knife (Diatome, Hatfield, PA). Ultrathin sections were collected on 200-mesh hexagonal copper grids and contrasted with saturated aqueous solutions of uranyl acetate and Reynold's lead citrate. Three to 5 sections from 2 to 3 randomly selected polymerized blocks per treatment were viewed with a transmission electron microscope (JEM 1400 Plus, Jeol USA Inc., Peabody, MA) oper- ated at $120 \mathrm{kV}$ and equipped with a high-performance CCD camera (Orius SC1000, Gatan Inc., Pleasanton, $\mathrm{CA}$ ). Images covering a wide range of magnifications $(500 \times$ to $30,000 \times)$ were collected from 10 to 20 randomly selected areas within different hexes on a grid. In total more than 1,200 images were recorded for this study, and the most representative images were selected for presentation.

\section{Image Analysis: Autocorrelation Function and Correlation Length Determination}

To develop quantitative data for the statistical analysis of protein density and to exclude human bias, we calculated the correlation length, $d$, as a measure of coarseness based on spatial autocorrelation functions applied to cropped micrographs of the casein matrix. In image analysis, spatial autocorrelation functions are used to determine length scales and orientation of structures being imaged (Pan et al., 2009). Suppose $I(x, y)$ is the continuous black and white intensity field associated with an image, sampled as a data raster with pixel locations $x_{i}, i=1,2, \ldots, N$ and $y_{j}, j=1,2, \ldots$, $M$, assumed to be evenly spaced over an area of extent $L_{x}$ by $L_{y}$. Image intensity was normalized so that its brightest and darkest pixels correspond to values of \pm 1 using the transformation

$$
f(x, y)=\frac{I(x, y)-\bar{I}}{\max [|I(x, y)-\bar{I}|]} .
$$

Here, $f$ is the normalized image field and $\bar{I}$ is the mean image intensity; using this formulation, $f(x, y)$ has mean zero, which simplifies the definition of the correlation function.

In integral form, the zero-normalized autocorrelation function (Pan et al., 2009) is defined as

$$
A(\xi, \eta)=\frac{1}{\|f\|_{2}^{2}} \iint_{-\infty}^{\infty} f(x, y) f(x-\xi, y-\eta) \mathrm{d} x \mathrm{~d} y
$$

where $\xi$ and $\eta$ are the correlation distances in $x$ and $y$, respectively, and

$$
\|f\|_{2}^{2}=\iint_{-\infty}^{\infty} f^{2}(x, y) \mathrm{d} x \mathrm{~d} y
$$

For a numerical intensity raster $\left[I\left(x_{i}, y_{j}\right)\right]_{(i, j)=(1,1)}^{(i, j)=(N, M)}$ with $N$ and $M$ both powers of 2 , the autocorrelation function can be calculated accurately and rapidly using the fast 
Fourier transform (Bracewell, 2000). In our case, image rasters $(2,048 \times 2,048$-pixel areas cropped from micrographs taken at an instrumental magnification of $30,000 \times ; \mathrm{n}=10$ per treatment and storage day) were imported directly into Matlab and analyzed using Matlab's built-in fast Fourier transform, fft2 (version 2014a, The MathWorks Inc., Natick, MA).

Based on the autocorrelation function, the correlation distance (length), $d$, was calculated as the first radial moment of $A$,

$$
d=\frac{\iint_{\Omega_{0.05}} \sqrt{\xi^{2}+\eta^{2}} A(\xi, \eta) \mathrm{d} \xi \mathrm{d} \eta}{\iint_{\Omega_{0.05}} A(\xi, \eta) \mathrm{d} \xi \mathrm{d} \eta}
$$

where $\Omega_{0.05}$ is the neighborhood around $(0,0)$ defined by $A(\xi, \eta) \geq 0.05$, which we took to be the lower threshold of possibly significant correlation. These integrals were calculated numerically using the 2-dimensional trapezoid rule to preserve accuracy.

\section{Statistical Analysis}

The aim of the current study was to understand the ultrastructural changes leading to a soft cheese texture in inadequately acidified feta cheese. Thus, the focus was on relative quantitative TEM and the evaluation of protein density by calculating correlation lengths as a measure of the spatial scale of structures in the casein matrix. Owing to possibly larger variability of ultrastructural features within a cheese treatment rather than between cheese treatments, it was imperative to compare data extracted from many representative micrographs that also met certain quality standardsnamely, not showing artifacts due to sample processing (e.g., variable section thickness and knife marks, inhomogeneous staining and contamination), microscope operation (e.g., alignment and focal planes), and image acquisition (e.g., image drift, image illumination and exposure times).

Between 14 and 44 micrographs from at least 10 fields of view per treatment were taken at an instrumental magnification of $30,000 \times$, and 10 micrographs of sufficient quality were selected for autocorrelation calculation. Differences in correlation lengths $(\mathrm{n}=10)$ were assessed by 2-way ANOVA followed by Tukey's multiple comparison tests. Differences were determined to be significant when $P<0.05$ (GraphPad Prism, version 6.0, GraphPad Software Inc., La Jolla, CA). Differences in the firmness of the 2 cheeses with different textural properties (and 1 intermediate) were evaluated by 1-way ANOVA followed by Tukey's multiple com- parison tests $(\mathrm{n}=5$ for compression and $\mathrm{n}=10$ for shear force measurements).

\section{RESULTS}

\section{Cheese Curd Ultrastructure}

The ultrastructure of curd during the manufacture of feta cheese is shown in Figure 1. Curd formation followed the typical pattern observed for other cheeses. Casein micelles in the milk gel (Figure 1, panel 1) were initially seen as cluster-linked colloidal particles. Upon the hydrolyzing action of chymosin, para-casein fused into chains and clumps. Uniformly dense fat droplets were randomly interspersed but without direct contact with the protein phase. Over time, there was consolidation and partial fusion of the casein micelles as shown by larger individual protein units that were more electron dense and in more defined strands (Figure 1, panel 2). There were still considerable voids between the protein strands, with a large proportion of the serum still being retained within the curd structure.

After curd and whey were transferred into molds, the curd was pressed under its own weight as it was no longer buoyed in the surrounding whey; more of the serum was subsequently expressed as whey. The effect of this on curd ultrastructure was apparent (Figure 1, panel 3). Individual chains of casein micelles grouped together and more crosslinks were apparent as the curd particles shrank and the protein aggregates fused together, entrapping numerous fat globules. Although the casein network now occupied a greater proportion of the curd volume, the protein phase was still discontinuous (Figure 1, panel 3).

Overnight fermentation at 35,20 , and $3^{\circ} \mathrm{C}$ resulted in cheeses with a range of $\mathrm{pH}$ values the next day $(\mathrm{pH} 4.80$, 4.88, and 5.17 for cheeses A, B, and C, respectively); most of the casein network then consisted of strands that were $1 \mu \mathrm{m}$ or more in width. Individual casein micelles were no longer observed (Figure 2, panels 1-3). At this point, no obvious differences in the organization of the casein matrix were discernable between the 3 experimental cheeses.

\section{Cheese Ultrastructure During Brining at Low Magnification}

During brining, the general pattern of graduated network consolidation continued for cheeses A and B, with protein strands becoming even thicker as seen in Figure 2, panels 4 and 5. After $90 \mathrm{~d}$ of cold storage, the casein matrix was still discontinuous in cheeses $\mathrm{A}$ and B (Figure 2, panels 7 and 8). This contrasted with a dense and continuous protein network in cheese $\mathrm{C}$ after 
only $7 \mathrm{~d}$ of storage in cold brine (Figure 2, panel 6). Serum pockets appeared reduced in size and fat globules were in close contact with the protein network. After 90 $\mathrm{d}$ of storage, another substantial change was observed,
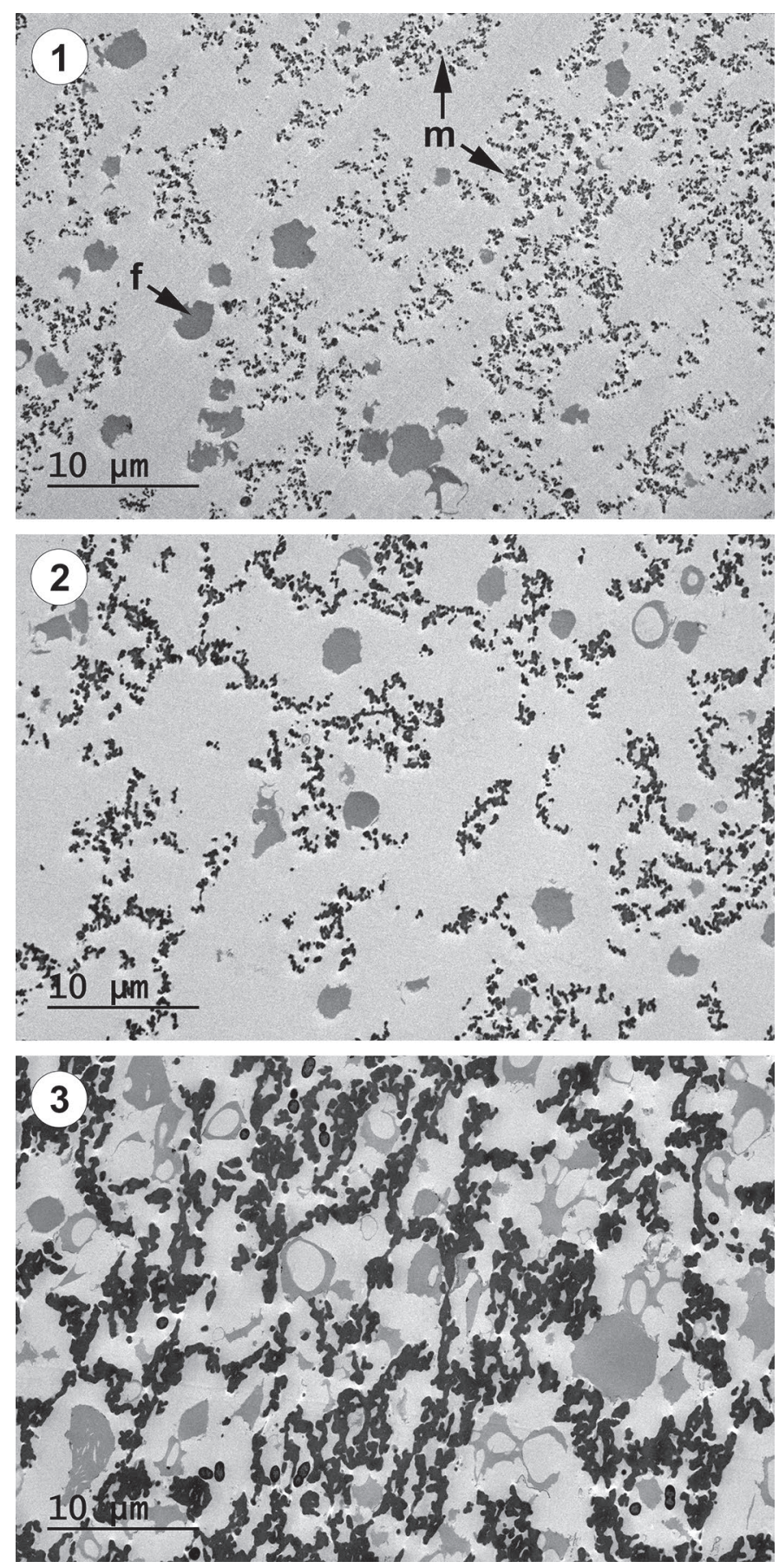

Figure 1. Low-magnification transmission electron micrographs of curd formation during manufacture of feta cheese and sampled before cutting ( $\mathrm{pH}$ 6.58; panel 1), after whey predraw ( $\mathrm{pH} 6.39$; panel 2), and after block formation before overnight fermentation ( $\mathrm{pH} 5.25$; panel 3 ). Instrumental magnification at $500 \times$, with the scale bar representing 10 $\mu \mathrm{m} . \mathrm{f}=\mathrm{fat} ; \mathrm{m}=$ casein matrix. with the casein matrix having become considerably less electron dense as indicated by lighter gray shades (Figure 2, panel 9). The matrix appeared to have expanded, encroaching into electron-opaque small and irregular remnants of serum pockets, thus tightly surrounding and often completely separating fat globules.

\section{Appearance and Texture of Aged Feta Cheese}

Cheese appearance after 4 mo of storage in cold brine is shown in Figure 3. The control cheese A had a white, compact appearance with irregular, typically almondshaped openings throughout the cheese mass. This is the result of ladling the curd into molds without additional compression. The cheese surface was moist but without a rind. In contrast, blocks from high-pH cheese $\mathrm{C}$ had not retained their initial shape when removed from the brine. They had a soft core with fewer and smaller irregular openings and a slimy, shiny surface from which material easily disintegrated and stuck to the cutting board. The appearance of cheese B was intermediate between that of cheeses A and C. Cheese B had a shiny, moist surface but without the slimy appearance. Irregular openings were still visible. No color differences were observed between the cheeses.

It is important to note that the relative differences in cheese $\mathrm{pH}$ persisted during the ripening period. After 4 mo of storage in cold brine, $\mathrm{pH}$ was $4.79,4.88$, and 5.04 for cheeses $\mathrm{A}, \mathrm{B}$, and $\mathrm{C}$, respectively, compared with the initial cheese $\mathrm{pH}$ of $4.80,4.88$, and 5.17 , respectively.

The difference in firmness between the cheeses was confirmed by measurement of hardness and maximum shear force (Figure 3). As pH of cheese increased, both the hardness $(P<0.001)$ and shear force $(P<0.001)$ decreased. Mean hardness for cheeses A, B, and C was $36.89,21.64$, and $5.20 \mathrm{~N}$, respectively, and maximum shear force was $3.02,1.36$, and $0.76 \mathrm{~N}$, respectively. Shearing profiles of cheese $\mathrm{C}$ were less jagged compared with those of control cheese A. This was indicative of cheese $\mathrm{C}$ having fewer holes and smaller mechanical openings as the shearing wire passed through them.

The softening of the high-pH cheese $\mathrm{C}$ during storage in cold brine was also noted during sampling for TEM from d 7 onward because manual cutting was necessary during initial sample preparation. Differences in appearance were likewise seen at $d 7$ but were more pronounced at d 90 .

\section{Cheese Ultrastructure During Brining at High Magnification}

When the protein network was examined at high magnification $(10,000 \times$ to $30,000 \times)$, it was apparent that changes had already started after the overnight 
Feta A

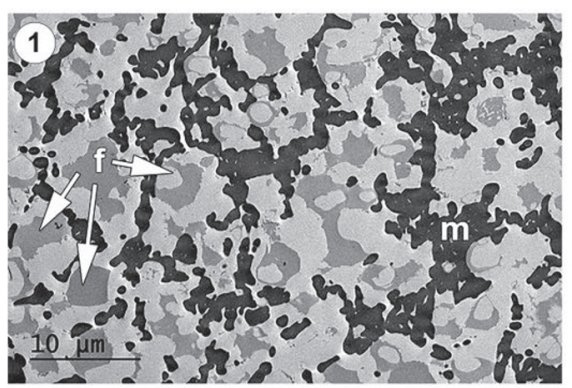

Feta B

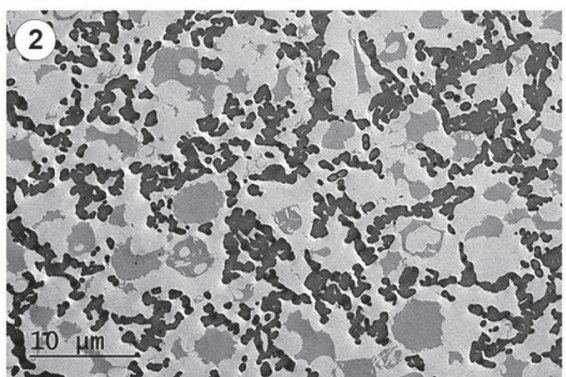

Feta C

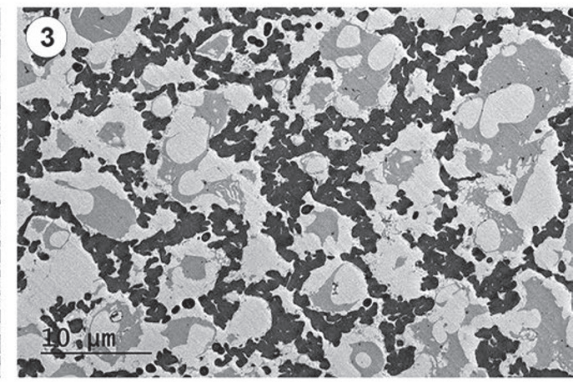

d 7
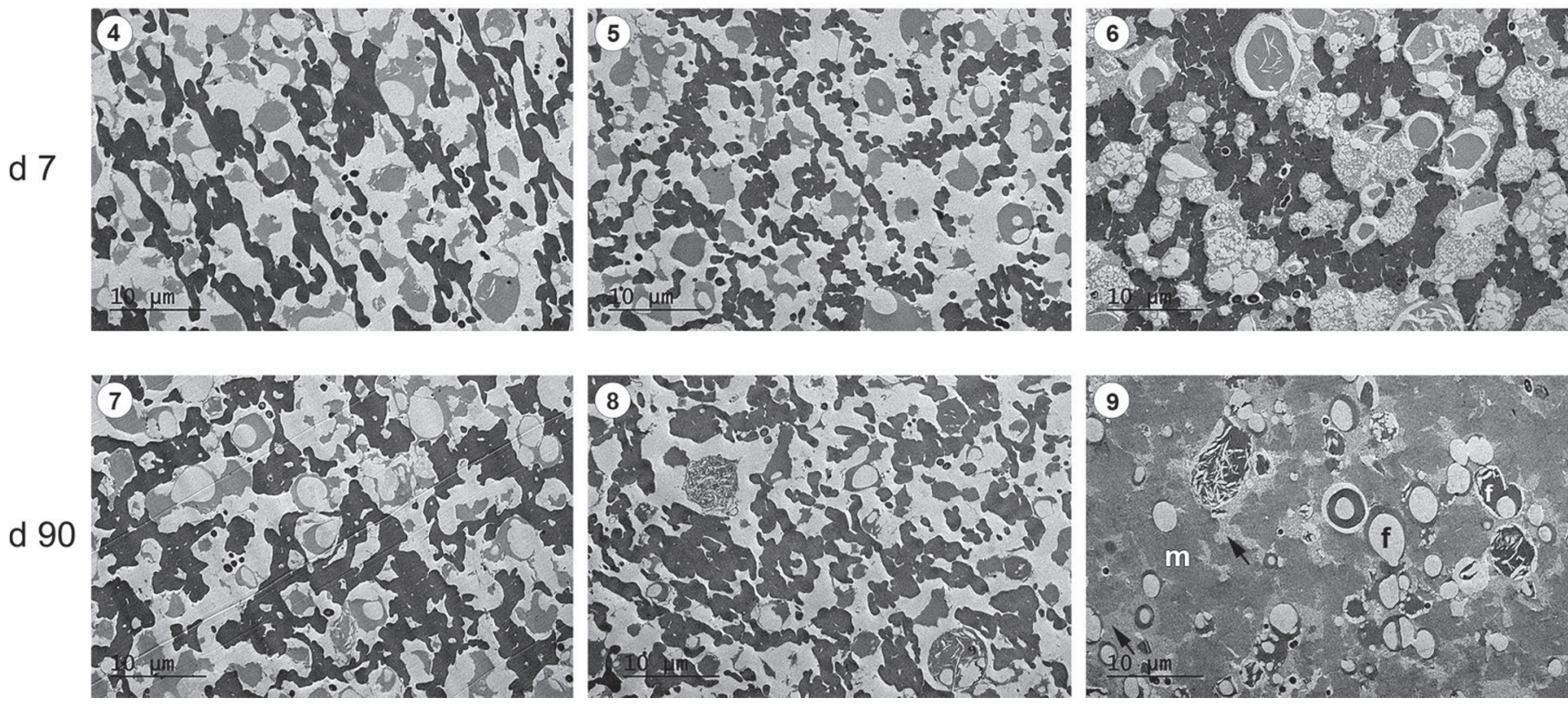

Figure 2. Low-magnification transmission electron micrographs of feta cheese after overnight fermentation $(\mathrm{d} 1)$ at $35^{\circ} \mathrm{C}($ feta $\mathrm{A}$, control), $20^{\circ} \mathrm{C}$ (feta B), and $3^{\circ} \mathrm{C}$ (feta $\mathrm{C}$ ) and after 7 and $90 \mathrm{~d}$ of storage in cold brine. Feta cheeses differed in $\mathrm{pH}$ after overnight fermentation ( $\mathrm{pH} 4.80$, 4.88 , and 5.17 for cheese $\mathrm{A}, \mathrm{B}$, and $\mathrm{C}$, respectively). Instrumental magnification at $500 \times$, with the scale bar representing $10 \mu \mathrm{m} . \mathrm{f}=$ fat; $\mathrm{m}=$ casein matrix.

fermentation step. As is evident from the micrographs in Figure 4, the casein matrix in cheeses $\mathrm{A}$ and $\mathrm{B}$ was uniformly electron dense, showing a finely granulated ultrastructure with occasional electron-opaque inclusions of very small $(<500 \mathrm{~nm})$ serum pockets (Figure 4, panel 1, white arrowheads). The casein matrix was coherent and clearly delineated from the surrounding serum phase. At this stage, the electron density of the high-pH cheese $\mathrm{C}$ appeared still comparable with that of cheeses A and B. However, in numerous areas fine particulate material was observed to dissociate from the periphery of the casein matrix into the serum phase (Figure 4, panel 3, black arrowheads).

After $7 \mathrm{~d}$ of cold storage, this fine particulate material had completely filled the space formerly occupied by the serum (Figure 5, panel 3). As a result, fat globules looked more spherical. They also had developed a "mottled" appearance with alternating areas of electron density. Compared with cheese C, cheeses A and B had a clearly defined casein matrix-serum interface with large electron-opaque areas indicative of serum pockets (Figure 5, panels 1 and 2).

After $90 \mathrm{~d}$ of cold storage, the interface was still detectable in cheeses A and B, albeit slightly less coherent in some areas of cheese B (Figure 6, panel 2). In the high-pH cheese $\mathrm{C}$, however, the interface was almost completely obliterated and replaced by a gradient of small clusters derived from the casein matrix (Figure 6, panel 3). Additionally, fat globules appeared to have more and well-defined crystalline inclusions. Fat globules were also much more electron dense compared with those seen in cheeses A and B, possibly related to a changed lipase activity with higher cheese $\mathrm{pH}$, thus affecting triglyceride composition and, subsequently, reactivity with the lipophilic staining agent osmium tetroxide during sample fixation. 


\section{Image Analysis of the Casein Matrix}

From the detailed examination of the casein matrix in transmission electron micrographs, particularly at high magnification $(30,000 \times$; representative images are shown in Figure 7A), it became evident that the ultrastructure had considerably changed over time in feta cheeses with higher cheese $\mathrm{pH}$ before brining. To quantify these differences, we calculated the autocorrelation. The idea of the autocorrelation function is to determine at what distance apart, on average, the pixels in the image tend to be similar to one another. The typical offset distances over which autocorrelation decays (the correlation length) is therefore a robust, nonparametric way to capture the spatial scale over which the structure dominates in an image without inflicting additional assumptions about sources of variability. Results from this analysis are presented in Figure 7B. Although the mean correlation length was not different in images of cheeses A through $\mathrm{C}$ after overnight fermentation, it was significantly different in cheese $\mathrm{C}$ after $7 \mathrm{~d}$ of cold storage and in cheese B after $90 \mathrm{~d}$ of cold storage $(P<$ 0.0001). At this time point, the mean correlation length also significantly differed between cheeses B and C $(P$ $<0.05$ ), with cheese $\mathrm{C}$ showing the largest degree of coarseness in the casein matrix.

\section{DISCUSSION}

Micro- and ultrastructural changes in the protein network and protein matrix, respectively, have been reported for many cheese varieties during the ripening process (Tunick et al., 1997) and have generally been linked to physicochemical changes and to the action of chymosin and other proteases in the milk leading to decreased density of the matrix with looser-appearing protein aggregates (Lawrence et al., 1987; Kiely et al., 1993; Guinee et al., 2002; Aminifar et al., 2010). Although a change in the density of the protein matrix in this study was observed during the aging of the ad-
Feta A
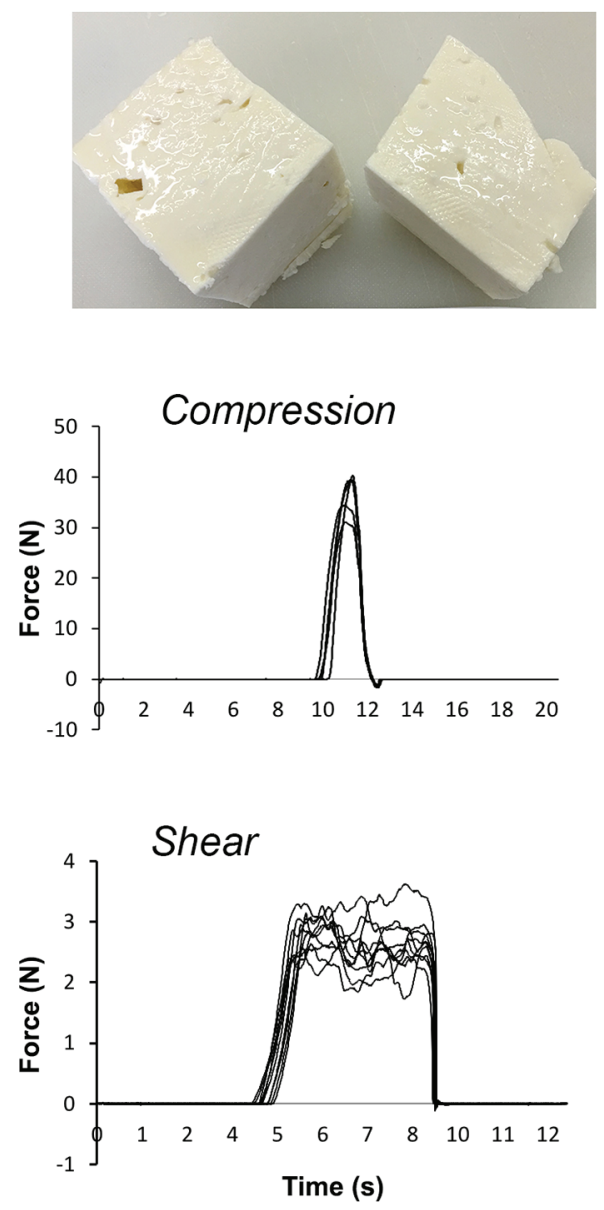

Feta B
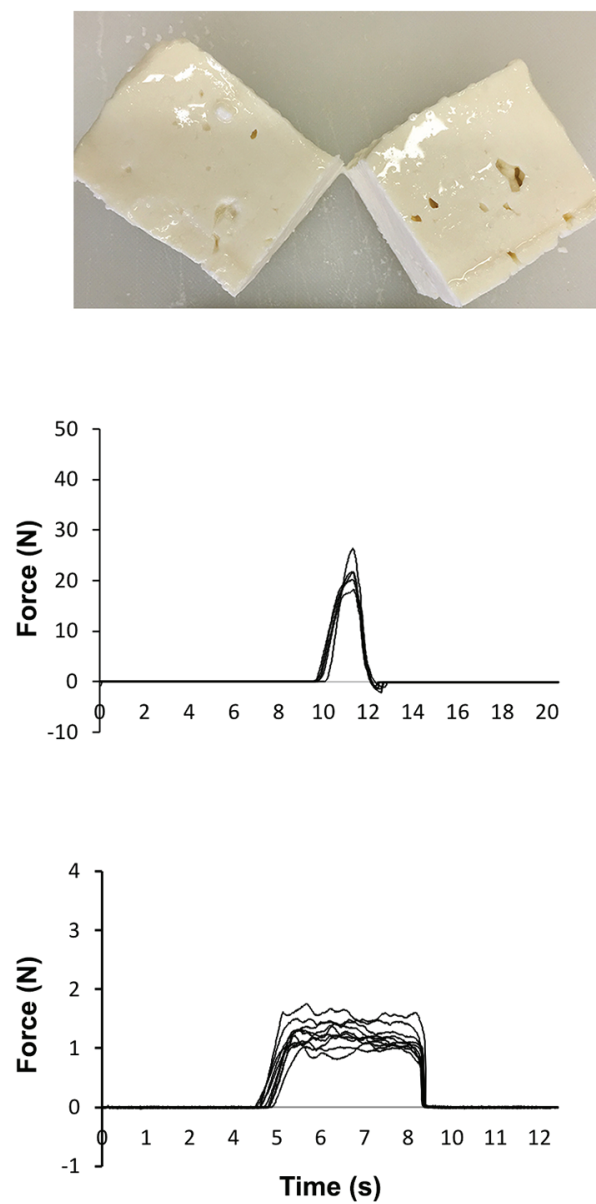
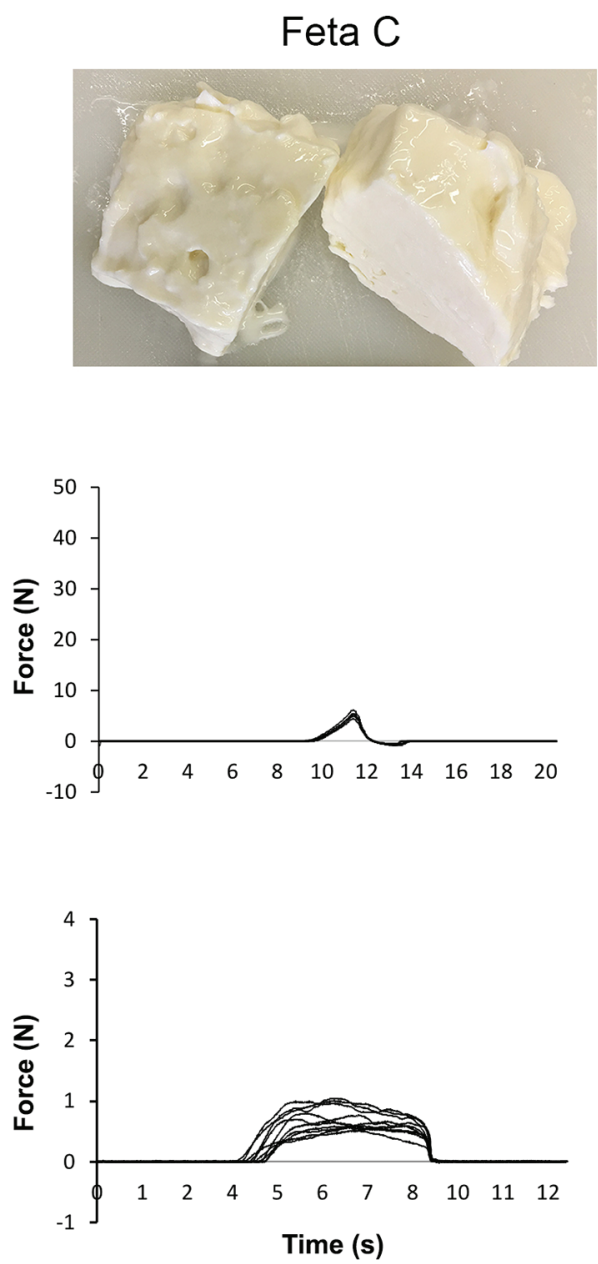

Figure 3. Appearance of feta cheeses with initial pH of 4.80 (feta A), 4.88 (feta B), and 5.17 (feta C) after 4 mo of storage in cold brine with corresponding force-time graphs testing for hardness by compression $(\mathrm{n}=5)$ and by shearing $(\mathrm{n}=10)$. 
equately acidified control feta cheese A, similar to that seen in aged mozzarella cheese (Cooke et al., 1995), the differences were only subtle and the overall open porous network structure, and thus texture, essentially remained unchanged over the tested ripening period. In contrast, when feta cheese was cooled during the fermentation resulting in a higher cheese $\mathrm{pH}$, it became apparent that the casein protein chains had not reached the point of insolubility. At the lower storage temperature, the hydrophobic interaction driving force that drove the initial aggregation of the renneted casein micelles, and the further fusion and shrinkage of the curd, was also removed. Under those conditions, some of the casein molecules became soluble and appeared as loosely aggregated material forming around the edges of the casein strands. At the higher $\mathrm{pH}$, the curd was no longer as firm and softened when immersed into the brine. Whether this change was fueled by differential proteolysis remains to be determined.

Although casein-associated calcium levels have been demonstrated to strongly influence texture by affecting protein-to-water interactions in mozzarella cheese (Metzger et al., 2001; Guinee et al., 2002; Joshi et al., 2004), it can be assumed that this plays less of a role in feta cheese because calcium progressively dissociates from the casein micelles below $\mathrm{pH}$ 5.2. This was also
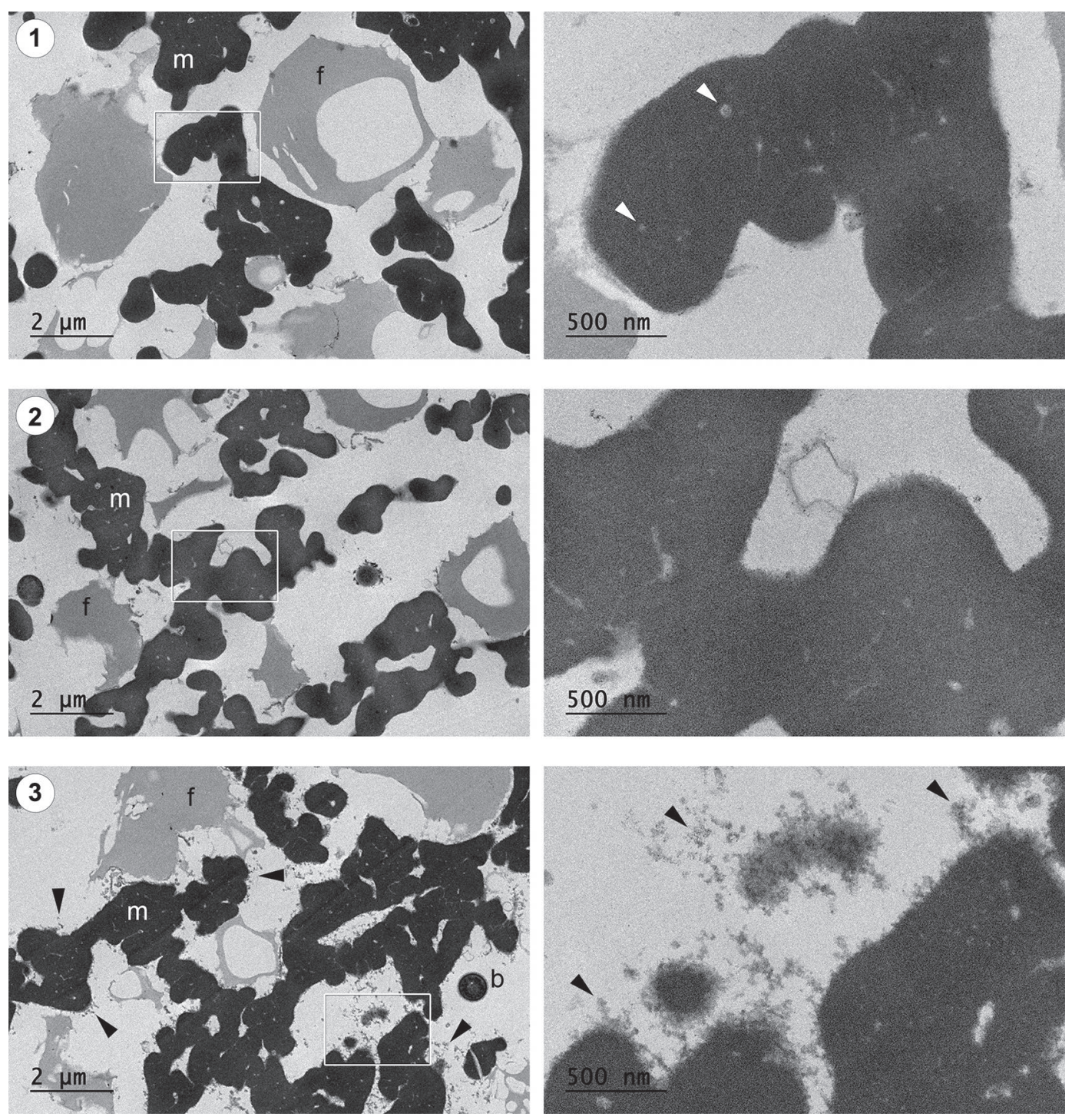

Figure 4. High-magnification transmission electron micrographs of feta cheese after overnight fermentation at $35^{\circ} \mathrm{C}$ (control, feta $\mathrm{A}$; panel 1 ), $20^{\circ} \mathrm{C}$ (feta B; panel 2), and $3^{\circ} \mathrm{C}$ (feta C; panel 3), resulting in different initial cheese $\mathrm{pH}$ before brining (pH 4.80, 4.88, and 5.17, respectively). The boxed areas in the micrographs on the left are enlarged on the right. White arrowheads point to small entrapped whey pockets within the casein matrix. Black arrowheads point to loosely connected particulate electron-dense material at the casein matrix-serum interface. Instrumental magnification at $2,000 \times$ and $10,000 \times$, respectively. $\mathrm{b}=$ bacteria; $\mathrm{f}=\mathrm{fat} ; \mathrm{m}=$ casein matrix. 
reported for cream cheese, a soft, unripened, acidprecipitated cheese with low cheese $\mathrm{pH}$ (Almena-Aliste and Kindstedt, 2005; Monteiro et al., 2009). However, in our experiments, part of the whey was used for making the brine, and therefore some of the calcium was still available in the system but presumably not bound to the casein matrix at a $\mathrm{pH}$ below 5.2. Inductively coupled plasma mass spectrometry measurements revealed similar $\mathrm{Ca}$ amounts in the cheese matrix of all 3 experimental cheeses $(208,228$, and $233 \mathrm{mg}$ of $\mathrm{Ca} / \mathrm{mg}$ of protein for cheeses $\mathrm{A}, \mathrm{B}$, and $\mathrm{C}$, respectively; preliminary data). Thus, a Ca-related effect does not seem likely as a driver for the observed functional changes.

It was noted throughout the sampling for TEM that the brine levels decreased in all experimental cheeses, with the lowest brine levels seen in the high-pH feta cheese C. Cheese moisture measurements also indicated a differential water migration pattern, with the cheese C having the highest moisture levels after $120 \mathrm{~d}$ of cold storage $(50.9,54.3$, and $58.8 \%$ for cheeses A, B, and $\mathrm{C}$, respectively; preliminary data). This $\mathrm{pH}$-dependent water absorption behavior was also seen by McMahon et al. (2009). It is therefore possible that the ultrastructural changes leading to a softening of the feta cheese body are related to changes in protein-to-water interactions causing the protein fibers to swell as they become more hydrated. Monteiro et al. (2009) similarly speculated that increased protein-to-water interactions caused the protein matrix to swell in experimentally softened cream cheese. In their study of the effect of
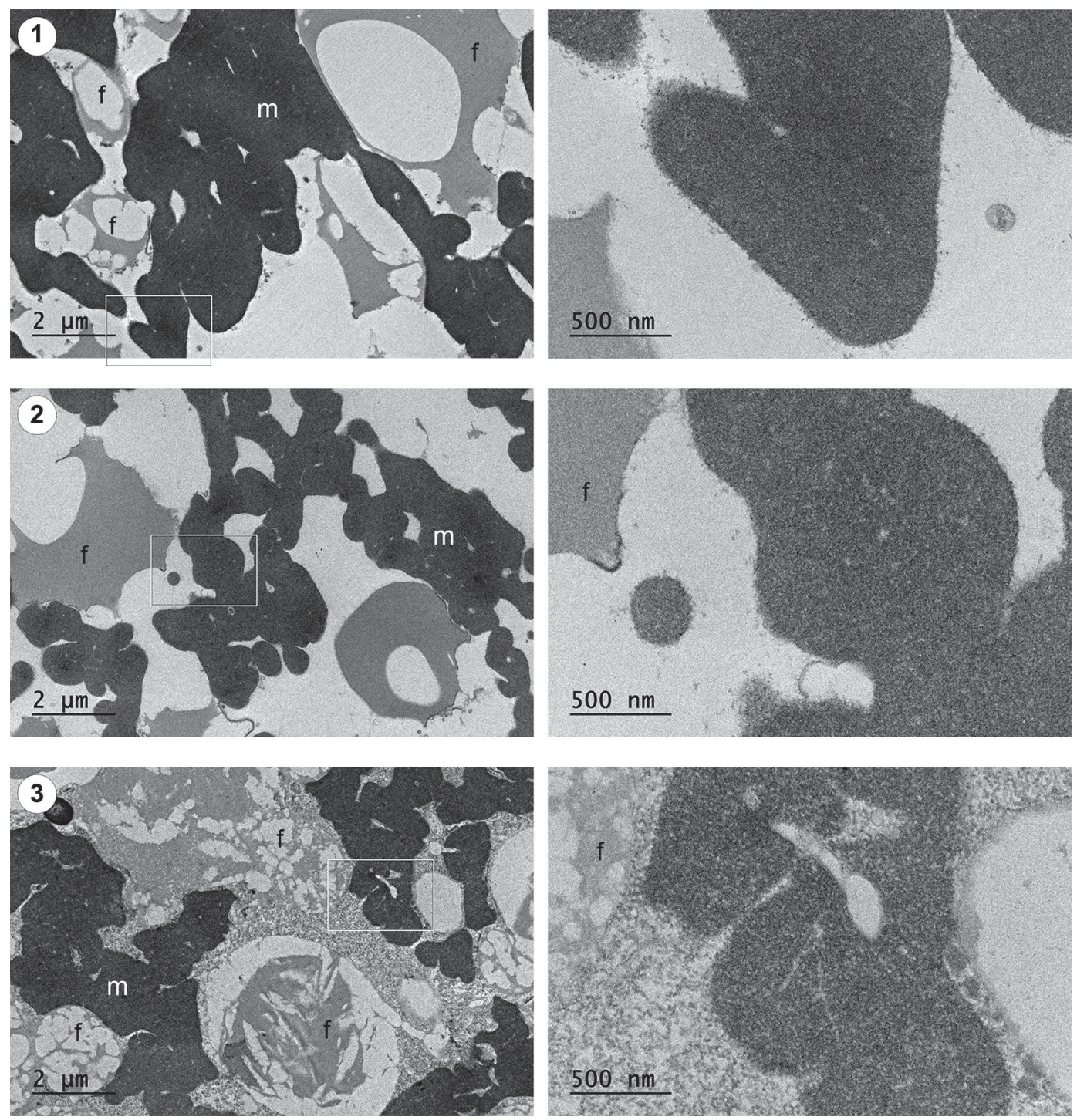

Figure 5. High-magnification transmission electron micrographs of feta cheeses (A, panel 1; B, panel 2; C, panel 3) that differed in initial cheese $\mathrm{pH}$ ( $\mathrm{pH} 4.80,4.88$, and 5.17, respectively) after $7 \mathrm{~d}$ of storage in cold whey brine. The boxed areas in the micrographs on the left are enlarged on the right. Instrumental magnification at $2,000 \times$ and $10,000 \times$, respectively. $\mathrm{b}=$ bacteria; $\mathrm{f}=$ fat; $\mathrm{m}=$ casein matrix. 

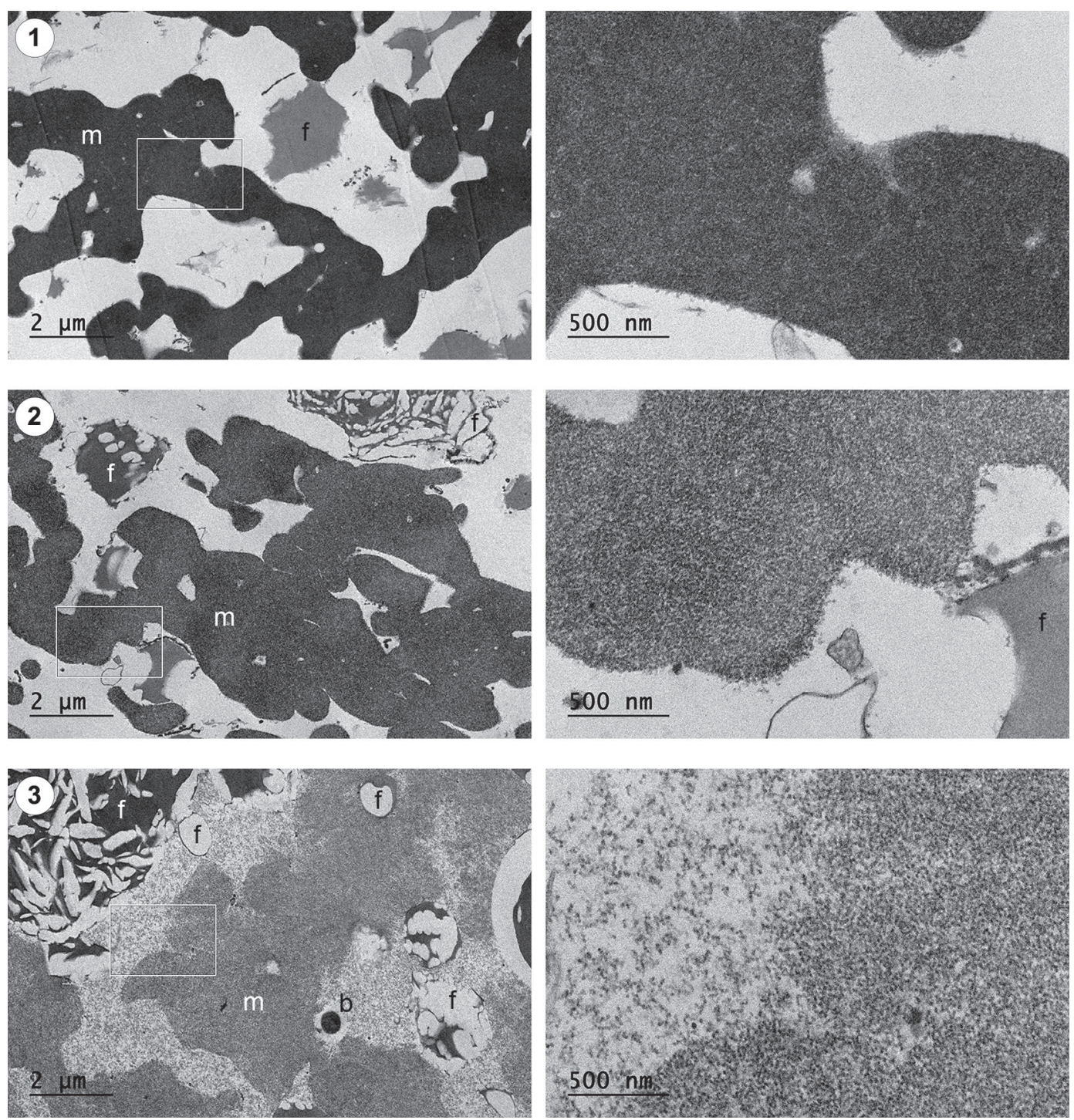

Figure 6. High-magnification transmission electron micrographs of feta cheeses (A, panel 1; B, panel 2; C, panel 3) that differed in initial cheese $\mathrm{pH}(\mathrm{pH} 4.80,4.88$, and 5.17, respectively) after $90 \mathrm{~d}$ of storage in cold whey brine. The boxed areas in the micrographs on the left are enlarged on the right. Instrumental magnification at $2,000 \times$ and $10,000 \times$, respectively. $\mathrm{b}=$ bacteria; $\mathrm{f}=$ fat; $\mathrm{m}=$ casein matrix.

$\mathrm{pH}$ on the microstructure and characteristics of cream cheese, samples were exposed postmanufacture to either ammonia (to increase cheese $\mathrm{pH}$ ) or acetic acid (to decrease cheese $\mathrm{pH}$ ) followed by analysis with scanning electron microscopy. They found that the corpuscular microstructure with a very fine, compact protein network in the control cream cheese $(\mathrm{pH}$ 4.92) showing imprints (but not actual fat globules) of few small fat globules changed to a coarse, open structure that was formed by networks of protein strands ( $\mathrm{pH}$ 4.04-4.48). On the other hand, the structure of the high-pH cream cheese ( $\mathrm{pH} 5.50-7.24)$ was characterized by a more continuous protein matrix formed around the imprints of multiple fat droplets. The authors argued that lowering the $\mathrm{pH}$ of cream cheese may have favored hydrophobic protein-to-protein interactions among the casein aggregates that caused the protein network structure to contract, whereas increasing the $\mathrm{pH}$ caused swelling of the protein network and increased the contact area between fat globules and the surrounding protein network with the fat globules appearing more spherical. In the present study, the protein phase was also noted in increased contact with the fat globules, making them more apparent in the high-pH feta cheese C.

The phenomenon of curd swelling was reported as early as 1972. Geurts et al. (1972) showed that the curd of fresh, unsalted Gouda cheese absorbed water after it was submerged in dilute brine for several days. Con- 
comitantly with water absorption, the swelling of casein was noted, forming a hydrated gel as a result of the peptizing action of the salt. Guo and Kindstedt (1995) extended these observations and proposed a model for age-related changes in the water phase of mozzarella cheese that assumes a progressive solubilization of intact caseins (mostly $\beta$-CN) from the swollen and hydrated casein matrix into the serum phase under the action of $\mathrm{NaCl}$. McMahon et al. (1999) came to a different conclusion based on changes in the microstructure of mozzarella cheese during cold storage. Immediately

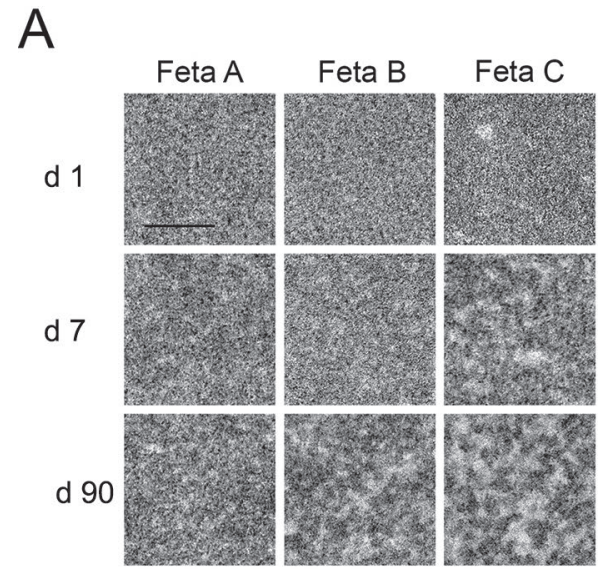

B

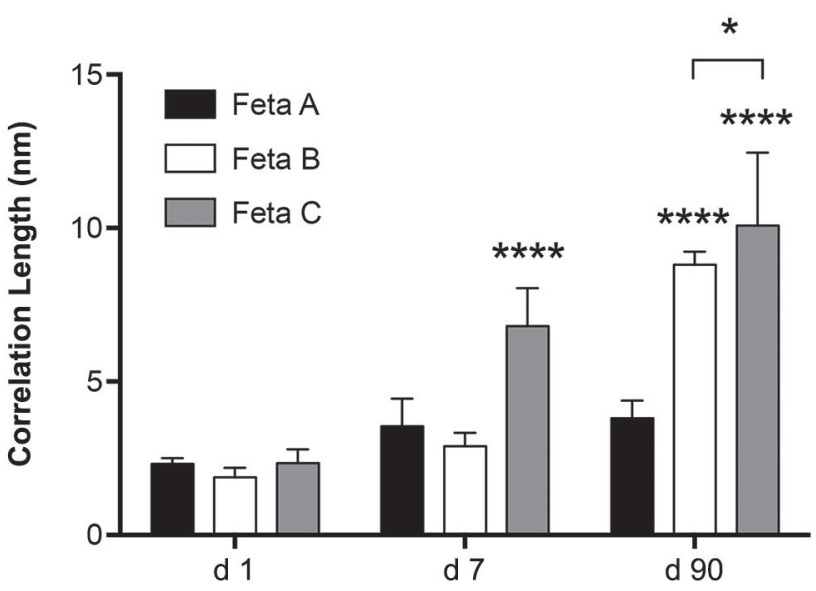

Figure 7. (A) Representative cropped areas from transmission electron micrographs illustrating the progressive changes in the ultrastructure of the casein matrix of aged feta cheeses that differed in initial cheese $\mathrm{pH}[\mathrm{pH} 4.80,4.88$, and 5.17 for feta $\mathrm{A}, \mathrm{B}$, and $\mathrm{C}$, respectively, after overnight fermentation (d 1) at 35,20 , and $3^{\circ} \mathrm{C}$, respectively, and after 7 and $90 \mathrm{~d}$ of storage in cold whey brine]. Instrumental magnification at 30,000×, with the scale bar representing $100 \mathrm{~nm}$. (B) Corresponding mean correlation lengths (with SD) as a measure of the spatial scale of structures in the casein matrix. Larger correlation lengths as seen in feta C, particularly after $90 \mathrm{~d}$ of storage in cold whey brine, indicate a higher degree of coarseness in the image and thus a decreased protein matrix density. $\mathrm{n}=10 .{ }^{*} P<0.05$ and **** $P<0.0001$ compared with control (feta A). after hot water stretching, the protein matrix formed smooth, elongated protein fibers separating the serum channels that contained fat, water, and bacteria. Over a 21-d period, they saw that the protein matrix had completely surrounded and sculpted the fat globules into discrete spherical aggregates, and they interpreted these changes as a function of the serum being absorbed into the protein matrix, with subsequent expansion of the matrix into the fat-serum channels. From the present study, it becomes evident that the protein matrix not only swelled but progressively dissociated from the periphery of the protein strands to fill the serum phase and engulf more spherical-appearing fat globules. Finally, it broke down completely, forming a continuous protein matrix with drastically decreased density.

An important question from the industry's as well as the home or artisanal cheese maker's point of view is the consideration of potential reversibility of these observed functional changes during aging. Could the softening of feta cheese be stopped and the characteristic texture still be achieved by adjusting the cheese $\mathrm{pH}$ to approximately 4.8 at some point during the cold storage? Could a batch of inadequately acidified feta cheese be salvaged, or are the dissociating casein filaments seen at d 1 an irreversible sign of the subsequent progressive ultrastructural changes leading to a less marketable texture and potentially altered flavor profile and shortened shelf life? (As a side note, no off flavors were detected in the 120-d-old cheese C.) McMahon et al. (2009) investigated a similar question when they alternated the brining temperature of feta cheese and measured the yield after 10 to 30 d. When feta cheese was stored for $10 \mathrm{~d}$ at $3^{\circ} \mathrm{C}$ the volume increased by about $15 \%$, which was generally also observed in our experimental cheeses, although not specifically measured. A subsequent $10-\mathrm{d}$ storage period at $22^{\circ} \mathrm{C}$ decreased the volume depending on salt concentration used in the brine. A third 10-d storage period at $3^{\circ} \mathrm{C}$ increased the volume again, but levels did not reach the original volume. When feta cheese was first stored at $22^{\circ} \mathrm{C}$ and then at $3^{\circ} \mathrm{C}$, the reduction of the volume was not reversible. Taken together, these experiments indicate a partial reversibility of the volume changes under certain storage conditions, but it should be noted that the fermentation temperature, not the storage temperature, largely determines the initial cheese $\mathrm{pH}$ and thus subsequent moisture uptake.

Almena-Aliste et al. (2006) also explored the potential reversibility of $\mathrm{pH}$-induced changes in cream cheese firmness, and they reported that firmness as well as the water-holding capacity (measured as the amount of expressible serum) followed a linear relationship and was fully reversible when the cheese $\mathrm{pH}$ was first 
increased and then subsequently decreased. The data presented here on the ultrastructure of softened feta cheese, however, are not supportive of a full, or even partial, reversibility. The protein matrix did not merely expand (i.e., swell) but also disintegrated to various degrees; therefore, a contraction of the protein phase is unlikely to result in complete restoration to its original organization. However, further experiments are needed to fully answer this question.

The aim of this study was to understand the structural mechanism leading to the observed change in cheese firmness during cold storage of insufficiently acidified feta cheese by analyzing the ultrastructure in great detail. Although we were able to explain the global mechanism in qualitative terms, as most of the structural changes were distinctive and therefore easily observable, we also needed to use image analysis methods to quantify some of the subtler changes. Image analysis is not always necessary but can be helpful when images appear similar, as seen, for example, in high-magnification micrographs of the protein matrix. To exclude human bias, we needed a numerical characterization of features that could be used to statistically compare these images. It was very challenging to find a metric that accurately quantified the differences in the density of the protein matrix as an indicator of hydration status. We used several image analysis processing methods, from basic tools in FIJI (Schindelin et al., 2012) to more advanced mathematical approaches. We calculated the percentage of dark area from binarized images after band-pass filtering and maximum entropy thresholding in FIJI as a proxy for protein density, but results were contradictory (data not shown). Other advanced image analysis methods (calculation of fractal dimension by various techniques, direct analysis of the Fourier spectrum for significant peaks, simple topological data analysis) also did not satisfactorily quantify all the differences that were visually apparent for certain conditions (data not shown). Others have used spectral analysis in ImageJ to calculate the spacing between electron-dense regions of the protein matrix (Cooke et al., 1995; Tunick et al., 1997; Paulson et al., 1998), but this approach did not work for the current data due to an absence of clear extrema in the Fourier spectrum. Fractal dimension analysis gave highly variable results, probably because the images were not truly self-similar across scales. Simple topological approaches (examining connectivity across scales) was likewise inconclusive, failing to extract significant differences among the images with consistency. However, the mean correlation distance is a robust measure of the length structures in an image and makes no assumptions regarding scale, so we were able to reliably quantify important differences and conclusively corroborate our qualitative assessment.

\section{CONCLUSIONS}

By systematically analyzing high-resolution TEM micrographs from key developmental points, for the first time a structural mechanism could be elucidated that clearly demonstrates the progressive nature of the functional change in aged feta cheese that was not acidified adequately before brining. The following sequence of events is at the base of the observed functional change. In feta cheese with high initial cheese $\mathrm{pH}$, casein proteins quickly (within hours) solubilized from the matrix and formed fine particulate material at various points along the edges of the casein strands. Concomitant with structural swelling, as indicated by a decrease in the matrix density, more material dissociated from the edges and completely filled the serum phase. The casein proteins were now in direct contact with individual spherical fat globules. The protein matrix broke down further and formed the continuous phase sculpting the embedded fat globules. Fewer protein-to-protein and more protein-to-water interactions make the protein matrix less rigid and easily deformed. The mechanical openings in the cheese body also disappeared as a function of the ultrastructural changes of the protein phase. In summary, not only ultrastructural swelling but the complete breakdown of the protein matrix resulting in the loss of the open porous and initially firm network structure is believed to be the cause of the softening of inadequately acidified feta cheese. Concomitant physicochemical changes remain to be investigated. Image analysis confirmed the observed ultrastructural changes in the density of the protein matrix, but results depended on the applied metric. The ultrastructural changes were progressive over time and were most readily observable in feta $\mathrm{C}$. With regard to $\mathrm{pH}$ of the cheese before brining, there appears to be a threshold of fermentation needed to prevent proteinaceous material from dissociating into the serum phase during storage in brine. Further research would be needed to determine the actual $\mathrm{pH}$ above which dissociation occurs and how this would be influenced by other factors, such as temperature and salt concentration of the storage brine and whether dry salting is used before brining.

\section{ACKNOWLEDGMENTS}

We thank Leprino Foods Company (Denver, CO) for supporting the Western Dairy Center at Utah State University (Logan). Electron microscopy was per- 
formed at the University of Utah Electron Microscopy Core Laboratory (Salt Lake City, UT). We acknowledge Karin Allen (Utah State University) for assistance in force-compression and shear measurements, Susan Durham (Utah State University) for statistical advice, and James J. Grande (GE Global Research, Niskayuna, NY) and Xiaojun Qi (Utah State University) for providing preliminary image analysis data. We appreciate the insightful comments by Carl Brothersen (Utah State University) and Federico Harte (Penn State University, State College, PA).

\section{REFERENCES}

Abd El-Salam, M. H., and E. Alichanidis. 2004. Cheese varieties ripened in brine. Pages 227-249 in Cheese Chemistry, Physics, and Microbiology. Vol. 2. Major cheese groups. P. F. Fox, P. L. H. McSweeney, T. M. Cogan, and T. P. Guinee, ed. Elsevier Academic Press, London, UK.

Aguilera, J. M. 2005. Why food microstructure? J. Food Eng. 67:3-11.

Almena-Aliste, M., M. L. Gigante, and P. S. Kindstedt. 2006. Impact of $\mathrm{pH}$ on the texture of cultured cream cheese: Firmness and water phase characteristics. Milchwissenschaft 61:400-404.

Almena-Aliste, M., and P. S. Kindstedt. 2005. Effect of increasing pH on texture of full and reduced-fat cream cheese. Aust. J. Dairy Technol. 60:225-230.

Aminifar, M., M. Hamedi, Z. Emam-Djomeh, and A. Mehdinia. 2010. Microstructural, compositional and textural properties during ripening of Lighvan cheese, a traditional raw sheep cheese. J. Texture Stud. 41:579-593.

Anifantakis, E. M. 1991. Greek Cheeses: A Tradition of Centuries. National Dairy Committee of Greece, Athens, Greece.

Bourne, M. C. 2002. Texture, viscosity, and food. Pages 1-32 in Food Texture and Viscosity: Concept and Measurement. Elsevier Science and Technology, Amsterdam, the Netherlands.

Bracewell, R. N. 2000. The Fourier Transform and its Application. McGraw-Hill Science, New York, NY.

Cooke, P. H., M. H. Tunick, E. L. Malin, P. W. Smith, and V. H. Holsinger. 1995. Electron-density patterns in low-fat mozzarella cheeses during refrigerated storage. Adv. Exp. Med. Biol. 367:311-320.

Cortez, M. A. S., M. M. Furtado, M. L. Gigante, and P. S. Kindstedt. 2008. Effect of $\mathrm{pH}$ on characteristics of low-moisture mozzarella cheese during refrigerated storage. J. Food Sci. 73:S443-S448.

Fox, P. F., P. L. H. McSweeney, T. M. Cogan, and T. P. Guinee. 2004. Cheese Chemistry, Physics and Microbiology. Vol. 2. 3rd ed. Elsevier Academic Press, London, UK.

Froehlich-Wyder, M. T., and H. P. Bachmann. 2004. Cheeses with propionic acid fermentation. Pages 141-156 in Cheese Chemistry, Physics, and Microbiology. Vol. 2. P. F. Fox, P. L. H. McSweeney, T. M. Cogan, and T. P. Guinee, ed. Elsevier Academic Press, London, UK.

Geurts, T. J., P. Walstra, and H. Mulder. 1972. Brine composition and the prevention of the defect "soft rind" in cheese. Neth. Milk Dairy J. 26:168-179.

Guinee, T. P., E. P. Feeney, M. A. Auty, and P. F. Fox. 2002. Effect of $\mathrm{pH}$ and calcium concentration on some textural and functional properties of mozzarella cheese. J. Dairy Sci. 85:1655-1669.

Guo, M. R., and P. S. Kindstedt. 1995. Age-related changes in the water phase of mozzarella cheese. J. Dairy Sci. 78:2099-2107.

Joshi, N. S., K. Muthukumarappan, and R. I. Dave. 2004. Effect of calcium on microstructure and meltability of part skim mozzarella cheese. J. Dairy Sci. 87:1975-1985.
Kalab, M., A. G. Sargant, and D. A. Froehlich. 1981. Electron microscopy and the sensory evaluation of commercial cream cheese. Scan. Electron Microsc. 14:473-482.

Kiely, L. J., P. S. Kindstedt, G. M. Hendricks, J. E. Levis, J. J. Yun, D. M. Barbano, H. D. Goff, C. J. Oberg, M. Rosenberg, and M. Kalab. 1993. Age related changes in the microstructure of mozzarella cheese. Food Struct 12:13-20.

Kindstedt, P. S., A. Zielinski, M. Almena-Aliste, and C. Ge. 2001. A post-manufacture method to evaluate the effect of $\mathrm{pH}$ on mozzarella cheese characteristics. Aust. J. Dairy Technol. 56:202-207.

Knoop, A. M., and W. Buchheim. 1980. Die unterschiedliche Entwicklung der Substruktur bei der Reifung von Harzer-, Tilsiter- und Camembert-Kaese. Milchwissenschaft 35:482-488.

Lawrence, R. C., L. K. Creamer, and J. Gilles. 1987. Texture development during cheese ripening. J. Dairy Sci. 70:1748-1760.

McMahon, D. J., R. L. Fife, and C. J. Oberg. 1999. Water partitioning in mozzarella cheese and its relationship to cheese meltability. J. Dairy Sci. 82:1361-1369.

McMahon, D. J., M. M. Motawee, and W. R. McManus. 2009. Influence of brine concentration and temperature on composition, microstructure, and yield of feta cheese. J. Dairy Sci. 92:4169-4179.

Metzger, L. E., D. M. Barbano, and P. S. Kindstedt. 2001. Effect of milk preacidification on low fat mozzarella cheese: III. Post-melt chewiness and whiteness. J. Dairy Sci. 84:1357-1366.

Monteiro, R. R., D. Q. Tavares, P. S. Kindstedt, and M. L. Gigante. 2009. Effect of $\mathrm{pH}$ on microstructure and characteristics of cream cheese. J. Food Sci. 74:C112-C117.

Pan, B., K. Qian, H. Xie, and A. Asundi. 2009. Two-dimensional digital image correlation for in-plane displacement and strain measurement: A review. Meas. Sci. Technol. 20:6.

Paulson, B. M., D. J. McMahon, and C. J. Oberg. 1998. Influence of sodium chloride on appearance, functionality, and protein arrangements in nonfat mozzarella cheese. J. Dairy Sci. 81:2053-2064.

Pollard, A., F. Sherkat, M. G. Seuret, and A. L. Halmos. 2003. Textural changes of natural cheddar cheese during the maturation process. J. Food Sci. 68:2011-2016.

Reis, P. J., and F. X. Malcata. 2011. Ripening-related changes in Serra da Estrela cheese: A stereological study. J. Dairy Sci. 94:12231238 .

Schiffman, S. 1977. Food recognition by the elderly. J. Gerontol. 32:586-592.

Schiffman, S. S., G. Musante, and J. Conger. 1978. Application of multidimensional scaling to ratings of foods for obese and normal weight individuals. Physiol. Behav. 21:417-422.

Schindelin, J., I. Arganda-Carreras, E. Frise, V. Kayning, M. Longair, T. Pietzsch, S. Preibisch, C. Rueden, S. Saalfeld, B. Schmid, J. Y. Tinevez, D. J. White, V. Hartenstein, K. Eliceiri, P. Tomancak, and A. Cardona. 2012. Fiji: An open-source platform for biological-image analysis. Nat. Methods 9:676-682.

Sheehan, J. J., and T. P. Guinee. 2004. Effect of pH and calcium level on the biochemical, textural and functional properties of reducedfat mozzarella cheese. Int. Dairy J. 14:161-172.

Spinnler, H.-E., and J.-C. Gripon. 2004. Surface-mold ripened cheeses. Pages 157-174 in Cheese Chemistry, Physics, and Microbiology. Vol. 2. P. F. Fox, P. L. H. McSweeney, T. M. Cogan, and T. P. Guinee, ed. Elsevier Academic Press, London, UK.

Szczesniak, A. S. 1963. Classification of textural characteristics. J. Food Sci. 28:385-389.

Tunick, M. H., P. H. Cooke, E. L. Malin, P. W. Smith, and V. H. Holsinger. 1997. Reorganization of casein submicelles in mozzarella cheese during storage. Int. Dairy J. 7:149-155.

Tunick, M. H., K. L. Mackey, J. J. Shieh, P. W. Smith, P. Cooke, and E. L. Malin. 1993. Rheology and microstructure of low-fat mozzarella cheese. Int. Dairy J. 3:649-662.

Twyman, R. M. 2005. Microscopy applications: Food. Pages 50-57 in Encyclopedia of Analytical Science. Vol. 6. 2nd ed. P. Worsfold, A. Townshend, and C. Poole, ed. Elsevier, London, UK. 